\title{
Palliative care in liver disease: what does good look like?
}

\author{
Hazel Woodland (D) , ${ }^{1}$ Ben Hudson, ${ }^{2}$ Karen Forbes, ${ }^{3}$ Anne McCune, ${ }^{4}$ \\ Mark Wright, ${ }^{5}$ On Behalf of the British Association for the Study of the \\ Liver (BASL) End of Life Special Interest Group
}

\begin{abstract}
'Department of Hepatology, University Hospitals Bristol NHS Foundation Trust, Bristol, UK 2Department of Hepatology, Royal Devon and Exeter NHS Foundation Trust, Exeter, UK ${ }^{3}$ Population Health Sciences, University of Bristol, Bristol, UK ${ }^{4}$ Department of Liver Medicine, University Hospitals Bristol NHS Foundation Trust, Bristol, UK ${ }^{5}$ Department of Hepatology, University Hospital Southampton, Southampton, UK
\end{abstract}

\section{Correspondence to}

Dr Hazel Woodland, Hepatology, University Hospitals Bristol NHS Foundation Trust, Bristol BS2 8HW, UK; hw17577@bristol. ac.uk

Received 4 July 2019 Revised 8 August 2019

Accepted 11 August 2019

Published Online First

10 September 2019

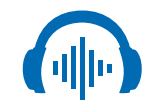

Listen to Podcast fg.bmj.com

\section{Check for updates}

(C) Author(s) (or their employer(s)) 2020. No commercial re-use. See rights and permissions. Published by BMJ.

To cite: Woodland $H_{\text {, }}$ Hudson B, Forbes K, et al. Frontline Gastroenterology 2020;11:218-227.

\section{ABSTRACT}

The mortality rate from chronic liver disease in the UK is rising rapidly, and patients with advanced disease have a symptom burden comparable to or higher than that experienced in other life-limiting illnesses. While evidence is limited, there is growing recognition that care of patients with advanced disease needs to improve. Many factors limit widespread provision of good palliative care to these patients, including the unpredictable trajectory of chronic liver disease, the misconception that palliative care and end-of-life care are synonymous, lack of confidence in prescribing and lack of time and resources. Healthcare professionals managing these patients need to develop the skills to ensure effective delivery of core palliative care, with referral to specialist palliative care services reserved for those with complex needs. Core palliative care is best delivered by the hepatology team in parallel with active disease management. This includes ensuring that discussions about disease trajectory and advance care planning occur alongside active management of disease complications. Liver disease is strongly associated with significant social, psychological and financial hardships for patients and their carers; strategies that involve the wider multidisciplinary team at an early stage in the disease trajectory help ensure proactive management of such issues. This review summarises the evidence supporting palliative care for patients with advanced chronic liver disease, presents examples of current best practice and provides pragmatic suggestions for how palliative and disease-modifying care can be run in parallel, such that patients do not miss opportunities for interventions that improve their quality of life.

\section{INTRODUCTION}

The mortality rate from chronic liver disease (CLD) in the UK has risen by

\section{Significance of this study}

- Hepatologists must develop the skills required to provide core palliative care to their patients, referring more complex cases to specialist palliative care services.

- Symptom burden in advanced liver disease is high, and frank discussions with patients and carers about individual priorities of care will enable symptom control to be optimised.

- Palliative care is not synonymous with end-of-life care and should be viewed as a means of optimising quality of life for patients and carers, in parallel with active management of chronic liver disease.

- An advanced liver disease multidisciplinary team (MDT) meeting provides an opportunity to identify and discuss supportive care needs of patients, clarify management plans and establish reasonable ceilings of care.

- Proactive management of hepatic encephalopathy can help to improve quality of life and reduce hospital admissions.

- Patients with advanced liver disease and their carers often have significant psychological, social and financial needs that need to be identified and supported as part of their chronic disease management.

around $400 \%$ since 1970 , in contrast to that of other life-limiting chronic diseases. ${ }^{1}$ Patients with compensated cirrhosis have a median survival of over 12 years; however, each year, 5\%-7\% progress to decompensated cirrhosis with a median survival of just 2 years. $^{2}$ Over $70 \%$ of patients with liver disease in England die in hospital, ${ }^{3}$ around $25 \%$ higher than the average for all deaths. ${ }^{4}$ The cost to the National Health Service (NHS) of treating liver disease is high and rising, estimated at $£ 2.1$ billion per year in 
2017. ${ }^{5}$ Physical symptom burden is high, comparable with that of patients with lung and colon cancer. ${ }^{6} \mathrm{~A}$ recently published systematic review found the most frequently reported symptoms in patients with endstage liver disease (ESLD) were pain, breathlessness, muscle cramps, sleep disturbance, depression, anxiety and erectile dysfunction; however, these issues are seldom addressed by hepatologists. ${ }^{7}$

The need for improvement in the care given to patients with ESLD towards the end of life (EOL) is increasingly recognised. Earlier institution of palliative care (PC) measures and advance care planning (ACP) discussions may allow patients and their carers to prepare better for disease progression and death. ${ }^{8-13}$ Unfortunately, changes in practice are slow, and many physicians will recognise the experience of Victoria Guy in 2006, as she witnessed her sister's death from alcohol-related liver disease.

\begin{abstract}
'At last, I realized, with absolute certainty and for the first time, that we were no longer helping my sister. I refused to watch her whimper and cry in pain any longer. I decided to be her advocate. I requested palliative care, and morphine was ordered ... With confidence, I told my sister we were trying to get her home, as she wished. This never happened. She died, in the hospital, 4 days later, at the age of $46 .^{14}$
\end{abstract}

As a registered nurse Guy reflected poignantly on the perceived deficiencies in her sister's care: the conflicting information given by healthcare professionals, the reluctance to admit how poor her sister's prognosis really was, inadequate pain relief, and the realisation, too late, that her sister's wishes had not been sought while she still had capacity to engage meaningfully in these conversations. ${ }^{14}$

\section{Role of early palliative and supportive care}

In 2014, the World Health Assembly acknowledged the importance of PC, including it in the definition of universal health coverage and recommending its integration into the treatment of patients with any lifelimiting condition. ${ }^{15}$ The WHO defines $\mathrm{PC}$ as:

\section{'an approach that improves the quality of life of patients and their families facing the problems associated with life-threatening illness, through the prevention and relief of suffering by means of early identification and impeccable assessment and treatment of pain and other problems, physical, psychosocial and spiritual. ${ }^{16}$}

While PC and EOL care are terms often used interchangeably, they are not synonymous. The official NHS definition of EOL care refers to care given to patients with a prognosis of 12 months or less. ${ }^{17}$ However, for many clinicians, EOL care refers to care given in the last days and weeks of life, where the trajectory of decline is predictable and ubiquitous. PC introduced at an early stage in the trajectory of advanced chronic disease has been shown to improve quality of life
(QOL) and symptom management, often in conjunction with ongoing active and potentially curative therapy. ${ }^{18} 19$ National Health Service (NHS) England states 'All professionals and staff in health and social care have a role in the effective provision of palliative and EOL care services across all care settings'. Professionals must acquire the skills to deliver 'core level', previously known as 'generalist', PC to their patients, referring only those with complex needs to specialist palliative care (SPC) services. ${ }^{20}$ The role of PC in ESLD remains poorly researched, with studies mainly focusing on SPC input in patients with hepatocellular carcinoma (HCC). A recent review concluded SPC input for patients with ESLD or HCC reduces costs, likelihood of death in hospital and encourages advance decision making, though evidence was heterogeneous and low quality. ${ }^{21}$ SPC referral rates for patients with ESLD remain low but are rising. In the USA, PC consultations for patients admitted with decompensated liver disease increased from just $0.97 \%$ in 2006 to $7.1 \%$ in 2012.22

\section{Barriers to PC}

Potential barriers to discussing PC and to SPC referral include patient, physician and service-related factors. For patients, a poor understanding of illness trajectory and role of PC can lead to unrealistic expectations and unwillingness to engage early with ACP discussions and SPC services. ${ }^{23}$ The onset of hepatic encephalopathy (HE) can also leave patients lacking capacity and unable to participate in ACP discussions. ${ }^{24}$ Two recent surveys of gastroenterologists, hepatologists and SPC physicians identified multiple concerns, including unclear criteria for SPC referral, discomfort with the role of SPC physicians in joint care, the belief $\mathrm{PC}$ is synonymous with EOL care, insufficient time to engage in complex discussions and uncertainty about appropriate medication for symptom control. $^{25} 26$ Despite this, the vast majority of gastroenterology and hepatology specialists $(86 \%)$ recognised patients with ESLD benefit from earlier PC input and also felt initial discussions regarding ACP should be initiated by themselves, as the responsible clinician, rather than by SPC physicians. $^{26}$

The perception that PC is mutually exclusive to disease modifying treatments and transplantation has been recognised as a key barrier in the timely initiation of core PC measures. ${ }^{1125}$ Although liver transplantation offers a potential cure, approximately 1000 transplants are carried out in the UK each year, while several thousand patients die from CLD annually. Around $15 \%$ of those listed will die or be removed from the waiting list each year. ${ }^{27} 28$ Evidence suggests patients active on the transplant list benefit from early SPC input, with a reduction in symptom burden and improved mood. ${ }^{29}$ Improving QOL for these patients, alongside those who are ineligible for transplant, is an important factor in delivering high-quality care. ${ }^{30}$ 


\begin{tabular}{|c|c|c|}
\hline & Supportive and Palliative Care Indicators Tool (SPICT) $)^{38}$ & Bristol Screening Tool ${ }^{39}$ \\
\hline Description & $\begin{array}{l}\text { Tool to help identify people with deteriorating health due to one or multiple } \\
\text { advanced conditions who may have unmet supportive and palliative care needs. } \\
\text { Includes general indicators of poor or deteriorating health alongside condition- } \\
\text { specific criteria. Suggested supportive care intervention is described for patients } \\
\text { meeting criteria. }\end{array}$ & $\begin{array}{l}\text { Prognostic screening tool used to identify patients } \\
\text { admitted with decompensated cirrhosis at high risk of } \\
\text { dying over the coming year. Suggested supportive care } \\
\text { intervention is described for patients meeting criteria. }\end{array}$ \\
\hline Criteria & $\begin{array}{l}\text { Either: advanced cirrhosis with } \geq 1 \text { complications in last year } \\
\text { Diuretic resistant ascites. } \\
\text { Hepatic encephalopathy. } \\
\text { Hepatorenal syndrome. } \\
\text { Bacterial peritonitis. } \\
\text { Recurrent variceal bleeds } \\
\text { or liver transplant contraindicated. }\end{array}$ & $\begin{array}{l}\text { Score of }>2 \text { from: } \\
\text { Child-Pugh Grade C. } \\
\text { Two liver-related admissions last } 6 \text { months. } \\
\text { Ongoing alcohol use (alcohol-related liver } \\
\text { disease patients). } \\
\text { Unsuitable for transplant work-up. } \\
\text { WHO performance status 3-4. }\end{array}$ \\
\hline
\end{tabular}

\section{PC IN ESLD: WHAT WORKS?}

\section{Parallel planning: early discussions about goals of care} and ACP

The unpredictable nature of ESLD and the challenge of accurately predicting prognosis ${ }^{31} 32$ has led to the concept of a 'parallel planning' approach to care. ${ }^{33}$ This strategy recognises the frequent need to actively manage complications, such as screening for varices, while also preparing patients and their families for the possibility their health could rapidly and unexpectedly deteriorate. $^{29}{ }^{34-37}$

Screening tools exist to help identify patients with CLD who have a particularly poor prognosis (see table 1) and who may benefit from SPC input. ${ }^{38} 39$ However, while acting as a useful prompt, these tools may inadvertently perpetuate the idea that ACP discussions should be delayed until the patient's condition has deteriorated significantly. Early conversations in clinic about prognosis and illness trajectory, even prior to the onset of decompensation, can ensure both patients and their relatives are better prepared if, or when, their disease progresses ${ }^{24}$ box 1 . A recent literature review found patients and carers consistently wanted more information about their disease and management options. ${ }^{40}$ Brisebois et $a l^{41}$ advocate embedding ACP discussions into the routine care of patients with cirrhosis, explaining the uncertain disease trajectory and exploring patients' changing priorities of care over time. They have produced a range of useful resources, including visual aids and question prompts, to help physicians initiate conversations at a pace that suits individual patients, acknowledging the poor health literacy of many patients by presenting information in various formats. Not all patients or their carers wish to engage in ACP discussions; however, information needs change over time and such discussions can be revisited, particularly as the illness progresses (box 1). ${ }^{23} 42$ Crucially, PC should not be considered the sole responsibility of SPC teams. Patients state consistently that they prefer to have ACP discussions with a clinician they are familiar with, rather than someone unknown to them. ${ }^{24}$ With limited resources and growing demand, hepatologists must develop the skills required to provide core $\mathrm{PC}$ to their patients, allowing SPC practitioners to concentrate on complex cases where their skills and experience are most needed. ${ }^{42}$

\section{Symptom control}

Improving QOL for patients and their families is the cornerstone of PC medicine. A recent review found improved management of $\mathrm{HE}$, ascites and malnutrition have the greatest impact on patients' QOL. ${ }^{43}$ Avoidance of hospital admissions has been identified by patients as an important goal, ${ }^{44}$ and educating and empowering patients and their carers to optimise symptom management themselves may help support this. For many patients, successful palliation involves both effective management of symptoms and relief of unnecessary burdens such as polypharmacy, and thus

\section{Box 1 Advance care planning in action}

A young homeless man with ongoing alcohol dependency and known cirrhosis with ascites, spontaneous bacterial peritonitis and recurrent variceal haemorrhage had over 15 admissions via the emergency department in the preceding 6 months. The case was discussed at an advanced liver disease MDT that resulted in a physiotherapy referral to help with breathlessness and referral to the community hospice team. Temporary housing was arranged by the hospice team, and the patient was given open access for day case paracentesis. An advance care plan was made with the patient during paracentesis sessions. He was clear that he did not want any further endoscopies and, in the case of further deterioration, he wished to die in hospital as he felt comfortable with the hepatology ward staff. An emergency treatment plan was written to clarify the limited plan for escalation of care, including use of midazolam in the event of a large gastrointestinal bleed. A Do Not Attempt Resuscitation form was completed and shared with the patient's community team. The patient was subsequently admitted acutely with a variceal bleed, sepsis and hepatic encephalopathy. Bleeding settled spontaneously, but he deteriorated further with sepsis and worsening encephalopathy. End of life care was managed in a side room on the ward as per the patient's wishes. 
medications and interventions should be regularly reviewed to ensure they are still warranted. ${ }^{45}$

Hepatic encephalopathy

$\mathrm{HE}$ is distressing for patients and carers, especially as they are often unaware that it is a potential complication of CLD until it occurs for the first time. ${ }^{4647}$ Treatment of both overt and covert HE has been found to significantly improve health-related QOL (HRQOL). ${ }^{48}$ Relatives are often best placed to notice subtle changes in personality and memory that indicate covert $\mathrm{HE}$ and should be empowered to both prevent and manage this condition. Unfortunately, one study found only $6 \%$ of patients and their carers knew they were on treatment for $\mathrm{HE}$ and understood how it worked. ${ }^{50}$ Encouraging patients and carers to adjust laxative and/or enema doses themselves may help improve QOL and avoid hospital admission. ${ }^{47}$ Recent studies examining the efficacy of rifaximin in clinical practice found, in combination with lactulose, it reduced both the frequency and length of hospital admissions 5152 confirming previous clinical trial findings. ${ }^{53}$ Thus in patients with advanced disease, early use of rifaximin should be encouraged. ${ }^{54}$

\section{Ascites}

Approximately $60 \%$ of patients with cirrhosis develop ascites, ${ }^{55}$ which has a significant negative impact on HRQOL. ${ }^{56} 57$ Emergency admissions for paracentesis are distressing and costly. Day case paracentesis services in England reduce healthcare costs, days spent in hospital and lead to a lower probability of dying in hospital, when compared with patients receiving exclusively unplanned paracentesis. ${ }^{58}$ This study epitomises the benefits of parallel planning, clearly demonstrating optimal chronic disease management is an important component of PC.

Long-term abdominal drains offer another option for patients with refractory ascites, particularly those too frail to use outpatient paracentesis services, and early evidence suggests the safety profile is comparable with that of large volume paracentesis. ${ }^{59} 60$ Patients with refractory ascites have a median survival of less than 6 months, ${ }^{55}$ and frank conversations about the balance of burdens and benefits will help physicians focus on individual priorities of care (box 2). Although not yet widely available, the alfapump offers another alternative for out of hospital drainage, with recent data from a randomised controlled trial showing improved HRQOL scores at 3 months compared with those undergoing large volume paracentesis. ${ }^{61}$

Diuretic therapy has an important role, although concern regarding deteriorating renal function or electrolyte imbalance frequently limits use. However, in patients reaching the EOL, it may be appropriate to take a pragmatic view and limit blood monitoring as part of a shared decision-making approach.

\section{Box 2 Parallel planning in action}

A middle-aged man with alcohol-related chronic liver disease, abstinent for several years but not suitable for liver transplant due to frailty. Patient had resistant ascites requiring paracentesis every $10-14$ days but was mobile and expressed a wish to avoid spending time in hospital. After further discussion, a shared decision was made to insert a long-term abdominal drain (LTAD). A joint consultation with a hepatology consultant and specialist palliative care consultant took place to discuss prognosis and ACP and patient reiterated desire to remain at home if possible, avoiding further admissions to hospital. After successful insertion, patient was eventually admitted when community blood tests demonstrated acute renal impairment. Initially, the amount of fluid removed via the LTAD was decreased but, after discussion with hepatology team, patient requested discontinuation of blood testing and removal of enough fluid to ensure comfort. Family was keen to care for patient at home therefore patient was discharged with anticipatory medications and community PC input. Patient survived a further 2 months at home and managed to go on a short holiday in the UK. He was cared for by family with support from district nurses and community PC team and moved to hospice for last few days of life as hepatic encephalopathy made care at home difficult. He died peacefully in the hospice.

\section{Malnutrition}

There is increasing recognition that frailty predicts poor outcomes in patients with cirrhosis, and sarcopenia is common in this group. ${ }^{62}$ An overnight fast in these patients has similar effects to a 72 hour fast in a healthy person. ${ }^{64}$ The European Association for the Study of the Liver (EASL) has produced comprehensive guidelines covering the management of nutrition ${ }^{65}$ and simple measures, such as encouraging patients to have a bedtime snack, have the potential to improve HRQOL. ${ }^{66}$ There is also evidence that optimising nutrition in patients with covert $\mathrm{HE}$ can improve cognition as well as HRQOL. ${ }^{43}$ Early dietitian referral is important, and all members of the healthcare team should emphasise the benefits of optimising nutrition to patients and carers.

\section{Pain management}

Concerns are often raised about metabolism and side effects of drugs, especially analgesics, in ESLD ${ }^{25}$ and advice regarding safe dosages is typically vague, encouraging caution. Despite a high pain and symptom burden, inadequate analgesic use is often reported by this group. ${ }^{6768}$ If improving QOL is the priority of care, then patients and carers need to discuss the relative merits of analgesics versus potential side effects, such as worsening HE. In order to improve consistency and confidence in prescribing, the BASL EOL Special Interest Group has recently published pragmatic guidelines for symptom control in advanced CLD (https:// www.basl.org.uk/index.cfm/content/page/cid/33). 


\section{Box 3 Case study 1}

Worthing collaboration between Western Sussex Hospitals NHS Foundation Trust and St Barnabas House Hospice - Advanced Liver Disease MDT and Community Liver Disease Nurse

Patients identified as having advanced chronic liver disease (CLD) are discussed at a monthly MDT consisting of hepatology and palliative medicine consultants, community liver disease nurse (CLDN), alcohol liaison services and social worker. Meeting enables identification of those patients who would benefit from referral to CLDN and other services, as well as agreement on appropriate medical interventions for next decompensation and coordination of care.

Patients referred to the CLDN receive a palliative care holistic assessment, including assessment of carer's/family needs. Patients are given the opportunity to participate in ACP discussions to express their priorities for future care and their preferences for place of death. Anticipatory care plans are then created and held with the patient, on electronic end of life register for paramedics, and in hospital notes.

After 2 years (2017-2018), 77\% (58/75) of patients dying from CLD had contact with specialist palliative care services, and $52 \%$ were referred to the CLDN. Hospital deaths comprised $61 \%$ overall, but for patients known to CLDN and hospice services, only $28 \%$ died in hospital-the remainder died at home or in the hospice.

\section{Coordinating care}

General practitioners (GPs) are keen to be closely involved in the care of patients with ESLD, although providing community-based care can be difficult where social circumstances are challenging. ${ }^{69} \mathrm{~A}$ recent qualitative study of GPs highlighted lack of expertise in hepatology, limited confidence with prognostication and a desire for ongoing support from secondary care as concerns. ${ }^{34}$ To bridge the gap between primary and secondary care, a recent feasibility study based in Edinburgh employed a Supportive Care Liver Nurse to improve care coordination, ACP and QOL for people with ESLD and their carers. The intervention was acceptable, effective in improving ACP, and resulted in several potential financial benefits, including a reduction in unplanned admissions, shorter stays in hospital and fewer primary care consultations. ${ }^{70}$ Case studies (boxes 3-6) highlight other UK centres that have established models to improve integration of primary and secondary care.

\section{Place of death}

There is growing evidence that, although patients and carers may state a preference for death at home, location is much less of a priority than comfort. ${ }^{71}$ In fact, death in hospital may be the preferred option for some patients with ESLD, especially those with unstable social situations. However, the stark discrepancy between the proportion of patients with CLD who die in hospital $(78 \%)$ and those with HCC $(39 \%)^{33}$

\section{Box 4 Case study 2}

Palliative care clinical nurse specialist (CNS) for liver services at Royal Free Hospital

An inpatient palliative care CNS, based within the palliative care (PC) team, is employed to work alongside the hepatology and hepatobiliary teams. This close working allows ease of referral, and the CNS attends regular board rounds to aid identification of patients with PC needs, including complex symptom control, psychological support, carer support, advance care planning and referral to community services. A weekly MDT has been established to identify and discuss the supportive and holistic care needs of those inpatients identified as having advanced disease.

The role involves active participation in research focusing on improving the care of patients with advanced CLD, including collaboration with the Marie Curie Palliative Care Research Department (University College London), in order to improve the quality of evidence available in this patient group. Additionally, there is a strong educational component, with the aim to empower other staff to recognise PC needs, improve knowledge, facilitate core PC delivery and recognise when specialist PC input is needed. The role has helped maintain a sustainable cultural change and referrals for specialist PC input for non-malignant liver disease have increased by $227 \%$ in 1 year.

suggests early conversations about priorities of care and place of death occur less frequently in patients with a non-malignant diagnosis. Unfortunately, many patients with ESLD have no carer, which can be a source of concern as their disease progresses; exploring ways to offer alternative support early is important and these conversations should be part of core PC delivery.

\section{Box 5 Case study 3}

\section{Exeter advanced liver disease MDT}

All patients with a new episode of decompensated liver disease are discussed at a monthly MDT attended by hepatologists, palliative care physicians, a dietitian, physiotherapist, occupational therapist (OT), alcohol support worker and a member of the community hospice team. Cases are discussed, and patients are triaged to the most appropriate services (eg, physiotherapy for patients with dyspnoea, OT for patients struggling in their home environment and palliative medicine for complex symptom control and ACP). A reasonable ceiling of care is agreed for each patient, which is subsequently discussed with the patient and their carer. In patients with very advanced disease, an emergency treatment plan is ratified, including preferred place of death and plan for managing decompensating events (eg, use of endoscopy in gastrointestinal bleeding). This appears at the top of the patient's online medical records such that it is immediately available to acute medical and emergency staff who may review the patient out of hours. 


\section{Box 6 Case study 4}

\section{Basildon Shared Care Liver Project}

The Shared Care Liver Project was established between St. Luke's Hospice and Basildon \& Thurrock University Hospital. The approach crosses traditional boundaries and gives patients and their carers access to the supportive care services of the hospice. Figure 1 illustrates the original pathway for patients with advanced chronic liver disease (dark green), and the blue boxes show the additional services offered to patients and their carers by St Luke's Hospice. The light green illustrates the interface between the two teams working collaboratively. This approach is now fully embedded into standard care for patients meeting criteria figure 1.

\section{Financial needs}

In the UK, the incidence of CLD is strongly associated with increasing socioeconomic deprivation. Furthermore, patients are typically of working age and often have dependants. ${ }^{33}$ When interviewed, both patients and carers acknowledge the financial strain that results from the disease. ${ }^{3444}$ The majority of carers of patients with CLD are partners or spouses and a significant number report having to give up or cut down the number of hours worked as a result of the demands of caring. ${ }^{7273}$ Some hospitals have teams available to help patients with benefits applications but, where these services are not available, it is important for physicians to be aware of local services or charitable organisations that can assist patients with this complex process.

\section{Do not forget the carers}

A report published by Carers UK in 2015 found the economic contribution made by unpaid carers is $£ 132$ billion per year, almost double its value in $2001 .^{74}$ Although positive aspects of caring are reported, it is an extremely challenging role, with multiple competing demands placed on people who, in most cases, do not have formal training. ${ }^{75}$ Factors that increase caregiver burden in ESLD include multiple hospitalisations, a history of HE, active alcohol use, additional dependents in the household and low household income. ${ }^{73}$ Ensuring carers are aware of local support services, as well as financial assistance they may be eligible for, acknowledges the importance and difficulty of their role. Patients often want carers to be involved in ACP discussions, recognising that if they lose capacity it is reassuring to know their carer is aware of their prior wishes and can be an effective advocate. ${ }^{24}$ Evidence suggests carers cope better with bereavement if their loved one received prolonged PC input prior to death. ${ }^{76}$

Table 2 summarises recommendations.

\section{WHERE DO WE GO FROM HERE?}

Many departments have acknowledged the complex needs of this group and designed novel models of care

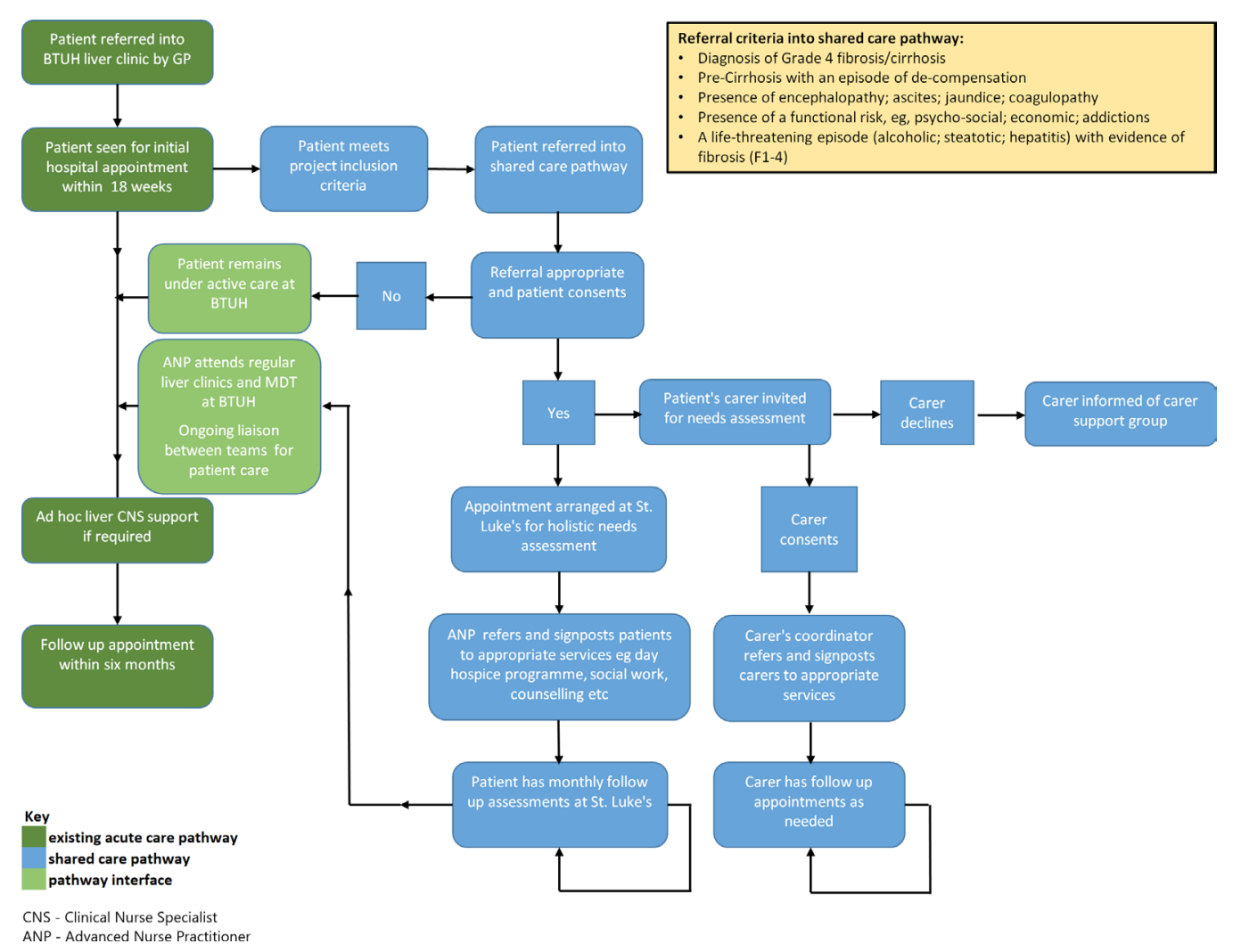

Figure 1 Shared care pathway St Luke's Hospice and Basildon \& Thurrock University Hospital. 


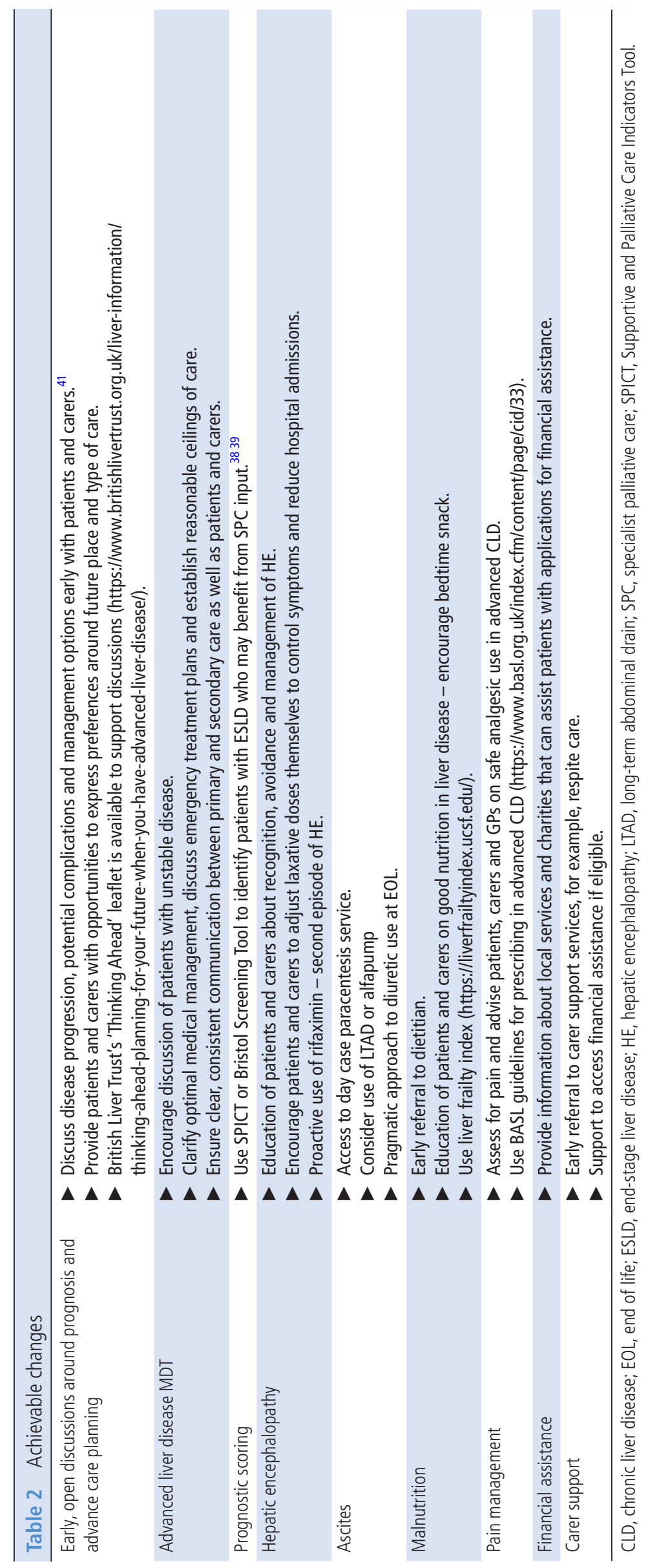


to address them; examples are summarised in the case studies. A key element of these approaches is recognition that conversations about prognosis and ACP take time, and adequate resources need to be allocated for these services to be effective. Unfortunately, without more evidence showing financial benefit, departments may struggle to secure funding for similar models. Trusts providing these services must monitor impact, audit actively and share findings widely to provide data to help other departments compile business cases. The Improving Quality in Liver Services scheme offers a useful 'choice architecture'to encourage widespread practice improvement. Inclusion of metrics that recognise the importance of high-quality coordinated care, early ACP discussions and PC input will enable impact to be evaluated.

For departments with constrained resources, an advanced liver disease MDT is an achievable goal. Liver disease is 'multi-dimensional', affecting people socially, psychologically and financially, as well as physically. Such MDTs encourage discussion of patients with unstable disease, for example, those with decompensated cirrhosis and should ideally comprise a hepatology consultant, liver specialist nurse, palliative medicine specialist, alcohol liaison nurse, pharmacist, dietitian, physiotherapist and social worker. The MDT aims to clarify optimal chronic medical management for patients, discuss emergency treatment plans, establish reasonable ceilings of care and consider holistically other factors that might improve QOL. MDT outcomes can guide future conversations with patients. A key part of effective working is ensuring good, consistent communication; plans can be shared with community teams (GP, district nurses, paramedics and hospice) as well as patients and their families to improve continuity of care.

Improved communication with patients and carers about disease trajectory, prognosis and management options is essential. Unfortunately, limitations on clinician time make this difficult to deliver in practice, and alternative methods for providing information are needed. Communication aids, such as question prompt lists, ${ }^{77}$ help to focus conversations onto patients' specific needs. Multimedia resources may also help, as limited literacy levels among many patents with CLD mean written resources are not always helpful.

Unfortunately, while interest in the role of PC in ESLD is growing, research has been limited to small non-randomised studies. Large-scale, highquality studies, such as the ongoing multicentred US-based study comparing different ways to offer PC to patients with CLD (https://hsrproject.nlm.nih. gov/view_hsrproj_record/20181694), are needed to evaluate the impact of early PC on patient-reported outcomes, as well as resource utilisation and care coordination. A higher profile at conferences may help to stimulate research interest in this field, for example, the recent EASL Postgraduate Course on
ESLD did not include any sessions on ACP or the role of PC.

Improved understanding of the role of PC among all healthcare workers is vital, and dispelling the myth that $\mathrm{PC}$ is synonymous with EOL care underpins this. PC should be viewed as a means of optimising QOL for patients and carers in parallel with active management of CLD. Limited SPC resources mean hepatologists need to take responsibility for core PC provision as they are best placed to identify and support patients who may benefit from ACP discussions. Gastroenterology trainees and specialist nurses need to receive robust practical training in the principles of PC to help achieve this. A proactive and methodical approach to parallel planning, with early ACP discussions can do much to avoid the experiences of Victoria Guy and her sister, which epitomise many failings of the current approach. We must recognise and seize all opportunities to improve our patients' quality of living as well as dying.

Acknowledgements Dr Suzanne Ford-Dunn from St Barnabas House Hospice, Virginia Campbell from St Luke's Hospice and Catherine Carroll from the Royal Free Hospital for their assistance in providing information for the case studies. Dr Katrina Curtis for her assistance with proofreading.

Contributors MW conceived the original idea for the review. HW performed the literature search, wrote the manuscript and is the guarantor for the article. $\mathrm{MW}, \mathrm{BH}, \mathrm{AM}$ and $\mathrm{KF}$ all read and edited early and final drafts of the review and contributed specialist clinical knowledge.

Funding The authors have not declared a specific grant for this research from any funding agency in the public, commercial or not-for-profit sectors.

Competing interests None declared.

Patient consent for publication Not required.

Provenance and peer review Commissioned; externally peer reviewed.

ORCID iD

Hazel Woodland http://orcid.org/0000-0002-9132-7396

\section{REFERENCES}

1 Williams R, Aspinall R, Bellis M, et al. Addressing liver disease in the UK: a blueprint for attaining excellence in health care and reducing premature mortality from lifestyle issues of excess consumption of alcohol, obesity, and viral hepatitis. Lancet 2014;384:1953-97.

2 D'Amico G, Garcia-Tsao G, Pagliaro L. Natural history and prognostic indicators of survival in cirrhosis: a systematic review of 118 studies. J Hepatol 2006;44:217-31.

3 National End of Life Intelligence Network. Deaths from liver disease: implications for end of life care in England, 2012. Available: http://www.endoflifecare-intelligence.org.uk/ resources/publications/deaths_from_liver_disease

4 Public Health England. Statistical commentary: end of life care profiles, 2018. Available: https://www.gov.uk/government/ publications/end-of-life-care-profiles-february-2018-update/ statistical-commentary-end-of-life-care-profiles-february-2018update

5 Williams R, Alexander G, Aspinall R, et al. New metrics for the Lancet standing Commission on liver disease in the UK. Lancet 2017;389:2053-80.

6 Roth K, Lynn J, Zhong Z, et al. Dying with end stage liver disease with cirrhosis: insights from support. study to 
understand prognoses and preferences for outcomes and risks of treatment. J Am Geriatr Soc 2000;48(S1):S122-30.

7 Peng J-K, Hepgul N, Higginson IJ, et al. Symptom prevalence and quality of life of patients with end-stage liver disease: a systematic review and meta-analysis. Palliat Med 2019;33:2436.

8 Boyd K, Kimbell B, Murray S, et al. Living and dying well with end-stage liver disease: time for palliative care? Hepatology 2012;55:1650-1.

9 Hope AA, Morrison RS. Integrating palliative care with chronic liver disease care. J Palliat Care 2011;27:20-7.

10 Iredale J. End-Stage chronic liver disease: time to define a good death. Hepatology 2008;47:1799-800.

11 Langberg KM, Kapo JM, Taddei TH. Palliative care in decompensated cirrhosis: a review. Liver Int 2018;38:768-75.

12 Rakoski MO, Volk ML. Palliative care and end-stage liver disease: a critical review of current knowledge. Curr Opin Gastroenterol 2019;35:155-60.

13 Mazzarelli C, Prentice WM, Heneghan MA, et al. Palliative care in end-stage liver disease: time to do better? Liver Transpl 2018;24:961-8.

14 Guy V. Liver failure, life support, family support, and palliation: an inside story. J Crit Care 2006;21:250-2.

15 World Health Assembly. Strengthening of palliative care as a component of integrated treatment throughout the life course: report by the Secretariat, 2014. Available: https://apps.who.int/ iris/handle/10665/158962

16 World Health Organisation. Who definition of palliative care, 2018. Available: http://www.who.int/cancer/palliative/ definition/en/

17 National Health Service. What end of life care involves, 2018. Available: https://www.nhs.uk/conditions/end-of-life-care/whatit-involves-and-when-it-starts/ [Accessed Aug 2019].

18 Haun MW, Estel S, Rücker G, et al. Early palliative care for adults with advanced cancer. Cochrane Database Syst Rev 2017;6:CD011129.

19 Kavalieratos D, Corbelli J, Zhang D, et al. Association between palliative care and patient and caregiver outcomes: a systematic review and meta-analysis. JAMA 2016;316:2104-14.

20 NHS England. Specialist level palliative care: information for commissioners, 2016. Available: https://www.england.nhs.uk/ wp-content/uploads/2016/04/speclst-palliatv-care-comms-guid. pdf

21 Mudumbi SK, Bourgeois CE, Hoppman NA, et al. Palliative care and hospice interventions in decompensated cirrhosis and hepatocellular carcinoma: a rapid review of literature. J Palliat Med 2018;21:1177-84.

22 Rush B, Walley KR, Celi LA, et al. Palliative care access for hospitalized patients with end-stage liver disease across the United States. Hepatology 2017;66:1585-91.

23 Kendall M, Carduff E, Lloyd A, et al. Different experiences and goals in different advanced diseases: comparing serial interviews with patients with cancer, organ failure, or frailty and their family and professional carers. J Pain Symptom Manage 2015;50:216-24.

24 Carbonneau M, Davyduke T, Spiers J, et al. Patient views on advance care planning in cirrhosis: a qualitative analysis. Can J Gastroenterol Hepatol 2018;2018:1-8.

25 Esteban JPG, Rein L, Szabo A, et al. Attitudes of liver and palliative care clinicians toward specialist palliative care consultation for patients with end-stage liver disease. J Palliat Med 2019;22:804-13.

26 Ufere NN, Donlan J, Waldman L, et al. Barriers to use of palliative care and advance care planning discussions for patients with end-stage liver disease. Clin Gastroenterol Hepatol 2019. doi:10.1016/j.cgh.2019.03.022. [Epub ahead of print: 15 Mar 2019].

27 Neuberger J. Liver transplantation in the United Kingdom. Liver Transpl 2016;22:1129-35.
28 NHS Blood and Transplant. Annual report on liver transplantation, 2018. Available: https://nhsbtdbe.blob. core.windows.net/umbraco-assets-corp/12250/nhsbt-livertransplantation-annual-report-2017-2018.pdf

29 Baumann AJ, Wheeler DS, James M, et al. Benefit of early palliative care intervention in end-stage liver disease patients awaiting liver transplantation. J Pain Symptom Manage 2015;50:882-6.

30 Potosek J, Curry M, Buss M, et al. Integration of palliative care in end-stage liver disease and liver transplantation. J Palliat Med 2014;17:1271-7.

31 Fox E, Landrum-McNiff K, Zhong Z, et al. Evaluation of prognostic criteria for determining hospice eligibility in patients with advanced lung, heart, or liver disease. support Investigators. study to understand prognoses and preferences for outcomes and risks of treatments. JAMA 1999;282:163845.

32 Freeborne N, Lynn J, Desbiens NA. Insights about dying from the support project. the study to understand prognoses and preferences for outcomes and risks of treatments. J Am Geriatr Soc 2000;48:S199-205.

33 Public Health England. The 2nd Atlas of variation in risk factors and healthcare for liver disease in England Sept, 2017. Available: http://fingertips.phe.org.uk/profile/atlas-of-variation

34 Kimbell B, Boyd K, Kendall M, et al. Managing uncertainty in advanced liver disease: a qualitative, multiperspective, serial interview study. BMJ Open 2015;5:e009241.

35 Larson AM, Curtis JR. Integrating palliative care for liver transplant candidates: "too well for transplant, too sick for life". JAMA 2006;295:2168-76.

36 Rakoski MO, Volk ML. Palliative care for patients with endstage liver disease: an overview. Clin Liver Dis 2015;6:19-21.

37 Low J, Vickerstaff V, Davis S, et al. Palliative care for cirrhosis: a UK survey of health professionals' perceptions, current practice and future needs. Frontline Gastroenterol 2016;7:4-9.

38 Highet G, Crawford D, Murray SA, et al. Development and evaluation of the supportive and palliative care indicators tool (SPICT): a mixed-methods study. BMJ Support Palliat Care 2014;4:285-90.

39 Hudson BE, Ameneshoa K, Gopfert A, et al. Integration of palliative and supportive care in the management of advanced liver disease: development and evaluation of a prognostic screening tool and supportive care intervention. Frontline Gastroenterol 2017;8:45-52.

40 Low JTS, Rohde G, Pittordou K, et al. Supportive and palliative care in people with cirrhosis: international systematic review of the perspective of patients, family members and health professionals. J Hepatol 2018;69:126073.

41 Brisebois A, Ismond KP, Carbonneau M, et al. Advance care planning (ACP) for specialists managing cirrhosis: a focus on patient-centered care. Hepatology 2018;67:2025-40.

42 Brighton LJ, Bristowe K. Communication in palliative care: talking about the end of life, before the end of life. Postgrad Med J 2016;92:466-70.

43 Bhanji RA, Carey EJ, Watt KD. Review article: maximising quality of life while aspiring for quantity of life in end-stage liver disease. Aliment Pharmacol Ther 2017;46:16-25.

44 Hudson B, Hunt V, Waylen A, et al. The incompatibility of healthcare services and end-of-life needs in advanced liver disease: a qualitative interview study of patients and bereaved carers. Palliat Med 2018;32:908-18.

45 Thompson J. Deprescribing in palliative care. Clin Med 2019;19:311-4.

46 Grønkjær LL, Andersen NG, Hansen LB, et al. Different views on hepatic encephalopathy: patients, relatives and nurses. Gastrointestinal Nursing 2016;14:S24-S31.

47 Künzler-Heule P, Beckmann S, Mahrer-Imhof R, et al. Being an informal caregiver for a relative with liver cirrhosis and overt 
hepatic encephalopathy: a phenomenological study. J Clin Nurs 2016;25:2559-68.

48 Prasad S, Dhiman RK, Duseja A, et al. Lactulose improves cognitive functions and health-related quality of life in patients with cirrhosis who have minimal hepatic encephalopathy. Hepatology 2007;45:549-59.

49 Sanyal A, Younossi ZM, Bass NM, et al. Randomised clinical trial: rifaximin improves health-related quality of life in cirrhotic patients with hepatic encephalopathy - a doubleblind placebo-controlled study. Aliment Pharmacol Ther 2011;34:853-61.

50 Montagnese S, Amato E, Schiff S, et al. A patients' and caregivers' perspective on hepatic encephalopathy. Metab Brain Dis 2012;27:567-72.

51 Oey R, Buck LEM, Erler N, et al. SAT-092-The efficacy and safety of rifaximin-a: a 2-year observational study of overt hepatic encephalopathy. J Hepatol 2019;70:e668.

52 Salehi S, Tranah TH, Lim S, et al. Rifaximin reduces the incidence of spontaneous bacterial peritonitis, variceal bleeding and all-cause admissions in patients on the liver transplant waiting list. Aliment Pharmacol Ther 2019;50:435-41.

53 Hudson M, Schuchmann M. Long-Term management of hepatic encephalopathy with lactulose and/or rifaximin: a review of the evidence. Eur J Gastroenterol Hepatol 2019;31:434-50.

54 Vilstrup H, Amodio P, Bajaj J, et al. Hepatic encephalopathy in chronic liver disease: 2014 practice guideline by the American association for the study of liver diseases and the European association for the study of the liver. Hepatology 2014;60:715-35.

55 European Association for the Study of the Liver. EASL clinical practice guidelines on the management of ascites, spontaneous bacterial peritonitis, and hepatorenal syndrome in cirrhosis. $J$ Hepatol 2010;53:397-417.

56 Marchesini G, Bianchi G, Amodio P, et al. Factors associated with poor health-related quality of life of patients with cirrhosis. Gastroenterology 2001;120:170-8.

57 Les I, Doval E, Flavià M, et al. Quality of life in cirrhosis is related to potentially treatable factors. Eur J Gastroenterol Hepatol 2010;22:221-7.

58 Hudson B, Round J, Georgeson B, et al. Cirrhosis with ascites in the last year of life: a nationwide analysis of factors shaping costs, health-care use, and place of death in England. Lancet Gastroenterol Hepatol 2018;3:95-103.

59 Macken L, Mason L, Evans C, et al. Palliative long-term abdominal drains versus repeated drainage in individuals with untreatable ascites due to advanced cirrhosis: study protocol for a feasibility randomised controlled trial. Trials 2018;19.

60 Macken L, Mason L, Bremner S, et al. SAT-076-Long term palliative abdominal drains versus large volume paracentesis in refractory ascites due to cirrhosis: a multi-centre feasibility randomised controlled trial (the reduce study). J Hepatol 2019;70:e660-1.

61 Stepanova M, Nader F, Bureau C, et al. Patients with refractory ascites treated with alfapump ${ }^{\circledR}$ system have better health-related quality of life as compared to those treated with large volume paracentesis: the results of a multicenter randomized controlled study. Qual Life Res 2018;27:151320.

62 Lai JC, Sonnenday CJ, Tapper EB, et al. Frailty in liver transplantation: an expert opinion statement from the American Society of transplantation liver and intestinal community of practice. Am J Transplant 2019;19:1896-906.

63 Lai JC, Feng S, Terrault NA, et al. Frailty predicts waitlist mortality in liver transplant candidates. Am J Transplant 2014;14:1870-9.

64 Johnson TM, Overgard EB, Cohen AE, et al. Nutrition assessment and management in advanced liver disease. Nutr Clin Pract 2013;28:15-29.

65 European Association for the Study of the Liver. Electronic address: easloffice@easloffice.eu, European Association for the Study of the Liver. EASL clinical practice guidelines on nutrition in chronic liver disease. J Hepatol 2019;70:172-93.

66 Tsien CD, McCullough AJ, Dasarathy S. Late evening snack: exploiting a period of anabolic opportunity in cirrhosis. $J$ Gastroenterol Hepatol 2012;27:430-41.

67 Desbiens NA, Wu AW, Broste SK, et al. Pain and satisfaction with pain control in seriously ill hospitalized adults: findings from the support research investigations. for the support Investigators. study to understand prognoses and preferences for outcomes and risks of Treatmentm. Crit Care Med 1996;24:1953-61.

68 Madan A, Barth KS, Balliet WE, et al. Chronic pain among liver transplant candidates. Prog Transpl 2012;22:379-84.

69 Standing H, Jarvis H, Orr J, et al. How can primary care enhance end-of-life care for liver disease? qualitative study of general practitioners' perceptions and experiences. BMJ Open 2017;7:e017106.

70 Kimbell B, Murray SA, Byrne H, et al. Palliative care for people with advanced liver disease: a feasibility trial of a supportive care liver nurse specialist. Palliat Med 2018;32:919-29.

71 Pollock K. Is home always the best and preferred place of death? BMJ 2015;351.

72 Miyazaki ET, Dos Santos R, Miyazaki MC, et al. Patients on the waiting list for liver transplantation: caregiver burden and stress. Liver Transpl 2010;16:1164-8.

73 Nguyen DL, Chao D, Ma G, et al. Quality of life and factors predictive of burden among primary caregivers of chronic liver disease patients. Annal Gastroenterol 2015;28:124-9.

74 Yeandle S, Buckner L, Carers V. 2015 - the rising value of carers' support: Carers UK, 2015. Available: https://www. carersuk.org/for-professionals/policy/policy-library/valuingcarers-2015

75 Stenberg U, Ruland CM, Miaskowski C. Review of the literature on the effects of caring for a patient with cancer. Psychooncology 2010;19:1013-25.

76 Wright AA, Zhang B, Ray A, et al. Associations between end-of-life discussions, patient mental health, medical care near death, and caregiver bereavement adjustment. JAMA 2008;300:1665-73.

77 J DS L, Vickerstaff V, Gola A, et al. Improving Communication in Medical Consultations for People with Advanced Liver Disease: The Development of a Question Prompt List (QPL) [abstract]. Palliat Med 2018;32(suppl 1):P101. 